\title{
Oral Status and Financial Accessibility to the Care of the Beneficiaries of the General Mutual of Officials and Agents of Côte d'Ivoire
}

\author{
Sangare Abou Dramane ${ }^{1,2, *}$, Samba Mamadou ${ }^{1,2}$, Meless Guanga David ${ }^{1,2}$, Akossi Claude Marcel ${ }^{3}$, \\ Datte Atta Sébastien ${ }^{2}$, Nouaman Nzebo Marcellin ${ }^{2}$, Nzore Kangah Serge ${ }^{2}$, Da-danho Viviane ${ }^{1,2}$, \\ Guinan Jean Claude ${ }^{1,2}$, Bakayoko-Ly Ramata ${ }^{1,2}$ \\ ${ }^{1}$ Department of Public Health, University Felix Houphouet-Boigny, Abidjan, Côte d'Ivoire \\ ${ }^{2}$ Laboratory of Public Health and Medicinal Plants, University Felix Houphouet-Boigny, Abidjan, Côte d'Ivoire \\ ${ }^{3}$ Dental Office, Bongouanou General Hospital, Côte d'Ivoire
}

Email address:

sangare_aboudramane@yahoo.fr (S. A. Dramane)

${ }^{*}$ Corresponding author

\section{To cite this article:}

Sangare Abou Dramane, Samba Mamadou, Meless Guanga David, Akossi Claude Marcel, Datte Atta Sébastien, Nouaman Nzebo Marcellin, Nzore Kangah Serge, Da-danho Viviane, Guinan Jean Claude, Bakayoko-Ly Ramata. Oral Status and Financial Accessibility to the Care of the Beneficiaries of the General Mutual of Officials and Agents of Côte d'Ivoire. Science Journal of Public Health.

Vol. 7, No. 5, 2019, pp. 174-180. doi: 10.11648/j.sjph.20190705.17

Received: September 4, 2019; Accepted: October 15, 2019; Published: October 28, 2019

\begin{abstract}
In many developing countries, the establishment of insurance mechanisms is recommended to remove the financial barrier related to access to care. In Côte d'Ivoire, the General Mutual of State Employees and Agents (Mugefci) pursues this objective. However, concerns remain about the ability of this prepayment mechanism alone to ensure effective consumption of oral health care. The purpose of this paper, which is to contribute to the optimal use of insurance mechanisms, was to assess the accessibility of the oral health care of Mugefci beneficiaries. The cross-sectional study, which was conducted by the Medical Service for Civil Servants, concerned Mugefci beneficiaries who had come for medical consultation. The data collected included decayed tooth indices, absent due to caries or obturated, the DMF index, the time of the recourse and the reasons for giving up dental care as well as the willingness to pay for the care. The numbers and frequencies related to these variables have been calculated. 216 Mugefci beneficiaries participated in the study. The prevalence of caries was $50.9 \%$, with a DMF index of 4.2. Self-medication was the first therapeutic remedy (47.7\%) and $18.1 \%$ of beneficiaries reported that they had given up care due to lack of money. $47.2 \%$ of beneficiaries had a poor perception of dental care. The study showed that the existence of health insurance does not guarantee effective access to care. The availability of a quality care offer, the improvement of insurance coverage and the information of the beneficiaries about the services offered are factors to be taken into account to ensure effective consumption of oral health care.
\end{abstract}

Keywords: Accessibility, Health Insurance, Oral Health, Satisfaction, Côte d'Ivoire

\section{Introduction}

The good health of the population is necessary for the development of any country. Indeed, investments in health are a key component of human capital formation and the sustainability of socio-economic development [1]. However, direct payments, which are the predominant mode of financing health care in many developing countries, can lead to impoverishment and catastrophic health expenditures for the people concerned [2]. In response to this situation, the World Health Organization (WHO) in 2010 recommended the use of advance payment to spread the financial risk over the entire population [3]. Thus, each country acquires means and mechanisms to respond to the needs of the population. However, in Côte d'Ivoire, as in most sub-Saharan countries, health financing has undergone many changes and remains problematic. 
From free health care in the aftermath of independence, funding policy has gone from cost recovery in the 1990s to today's insurance mechanisms $[4,5]$. The various measures taken by the authorities each time aimed to ensure greater financial accessibility to health care for the population. Indeed, studies have shown that the population faces financial difficulties in accessing oral health care $[6,7]$. The issue of accessibility to care remains a concern for oral health in Côte d'Ivoire. The General Mutual of Civil Servants and State Agents of Côte d'Ivoire (Mugefci) institution of solidarity and mutual aid for the benefit of civil servants should facilitate access to care, including oral care. However, does the existence of an insurance mechanism such as Mugefci guarantee effective consumption of care? In order to better assess the contribution of health insurance to improving access to oral health care, this study was conducted among beneficiaries of the General Mutual of State officials and agents of the Ivory Coast (Mugefci). The objective was to analyze the oral health care consumption of the beneficiaries of this health mutual.

\section{Methods}

\subsection{Type and Area of the Study}

The transversal study was carried out within the framework of the Civil Servants' Medical Service (SMF), commonly known as the "Civil Servants' Hospital", a health establishment created by Mugefci. Several health services are provided, including: general medicine, dentistry, ophthalmology, cardiology, gynaecology, Otorhinolaryngology, radiology, pediatrics, biological analyses and functional investigations.

\subsection{Study Population, Selection Criteria, Sample Size}

The study concerned the beneficiaries of Mugefci, the main health mutual of the Coast with more than 700,000 beneficiaries (members and beneficiaries). Included in the study was any Mugefci beneficiary for at least one year, who had come to SMF for a consultation other than dental, and who had agreed to participate in the study. The study sample size was 216 subjects. It was calculated using the Schwartz formula $\left(\mathrm{n}=\mathrm{z} \alpha^{2} \mathrm{pq} / \mathrm{i}^{2}\right)$ with a frequency of people who gave up oral health care of $17 \%$ and a risk $\alpha=5 \%$.

\subsection{Data Collection and Variables Studied}

The data were collected by a single interviewer to minimize information bias. A standardized face-to-face interview questionnaire was used to collect information related to the socio-demographic characteristics of respondents, how they used oral health care and how they perceived their oral health before and after joining Mugefci. Perception was measured on a score scale ranging from 0 (very poor perception) to 10 (very good perception). Then, a clinical examination form was used to collect data on dental status. The main variables were for the oral state: the decayed, missing tooth indices and the DMF index.

\subsection{Data Analysis}

The use of the data made it possible to estimate statistical parameters for these variables (mean, percentage, standard deviation). The analysis of these parameters based on the Chi-square statistical test, with a 5\% risk, allowed comparisons to be made.

\section{Results}

\subsection{Socio-demographic Profile of Mugefci Beneficiaries}

Table 1. Socioeconomic characteristics of respondents.

\begin{tabular}{lll}
\hline Socio-economic variables & Number (n) & Percentage (\%) \\
\hline Sex & & \\
Male & 118 & 54.6 \\
Female & 98 & 45.4 \\
Place of residence & & \\
Abidjan & 118 & 54.6 \\
Out of Abidjan & 98 & 45.4 \\
Complementary insurance & & \\
Yes & 201 & 93.1 \\
No & 15 & 6.9 \\
Total & 216 & 100,0 \\
\hline
\end{tabular}

The majority of Mugefci beneficiaries surveyed were male, residing in Abidjan and having supplementary insurance in addition to the MUGEFCI basic scheme.

\subsection{Oral Health Status and Care Needs}

Table 2. Description of dental status of Mugefci beneficiaries.

\begin{tabular}{lllll}
\hline Indice & D & M & F & DMF \\
\hline Counting & 241 & 442 & 223 & 906 \\
Index value & 1.1 & 2.0 & 1.0 & 4.2 \\
Proportion of decayed teeth in the DMF & $26.6 \%$ & & & \\
Proportion of missing teeth in the DMF & $48.8 \%$ & & \\
Proportion of filled teeth in the DMF & $24.6 \%$ & & \\
\hline
\end{tabular}

$\mathrm{D}=$ Decayed, $\mathrm{M}=$ Missing, $\mathrm{F}=$ Filled.

The level of caries achieved by Mugefci beneficiaries was moderate $(\mathrm{CAO}=4.1)$ with a significant proportion of missing teeth $(48.8 \%)$.

Table 3. Description of dental status of Mugefci beneficiaries by sex.

\begin{tabular}{|c|c|c|c|c|c|c|c|c|}
\hline \multirow{2}{*}{$\frac{\text { Sex }}{\text { Index }}$} & \multicolumn{4}{|c|}{ Male $(n=118)$} & \multicolumn{4}{|c|}{ Female $(n=98)$} \\
\hline & D & M & $\mathbf{F}$ & DMF & D & M & $\mathbf{F}$ & DMF \\
\hline Counting & 127 & 223 & 94 & 444 & 114 & 219 & 129 & 462 \\
\hline Index value & 1.1 & 1.9 & 1.0 & 3.8 & 1.2 & 2.2 & 1.2 & 4.7 \\
\hline Proportion of decayed teeth in the DMF & $28.6 \%$ & & & & $24.7 \%$ & & & \\
\hline Proportion of missing teeth in the DMF & $50.2 \%$ & & & & $47.4 \%$ & & & \\
\hline Proportion dents obturées & $21.2 \%$ & & & & $27.9 \%$ & & & \\
\hline
\end{tabular}

$\mathrm{D}=$ Decayed, $\mathrm{M}=$ Missing, $\mathrm{F}=$ Filled. 
The level of carious disease is high in women $(\mathrm{DMF}=4.7)$ and moderate in men $(\mathrm{CAD}=3.8)$. However, oral health care needs are higher among men with the proportions of decayed and missing teeth at $28.6 \%$ and $50.2 \%$ respectively.

Table 4. Distribution of feeling of need for unmet oral health care.

\begin{tabular}{lllll}
\hline \multirow{2}{*}{ Feeling of need for oral care } & Yes & No & Don't know & Total \\
\cline { 2 - 5 } & $\mathbf{n}(\mathbf{\%})$ & $\mathbf{n ~ ( \% )}$ & $\mathbf{n ~ ( \% )}$ & $\mathbf{n}(\%)$ \\
\hline Female & $41(41.8)$ & $29(29.6)$ & $28(28.6)$ & $98(100.0)$ \\
Male & $58(49.2)$ & $30(25.4)$ & $30(25.4)$ & $118(100.0)$ \\
Total & $99(45.8)$ & $59(27.3)$ & $58(26.9)$ & $216(100.0)$ \\
\hline
\end{tabular}

$45.8 \%$ of respondents believe they have unmet oral health needs. The difference between women and men was not statistically significant $(\mathrm{p}=0.558)$.

\subsection{Accessibility to Oral Health Care for Mugefci Beneficiaries}

\subsubsection{Therapeutic Itinerary}

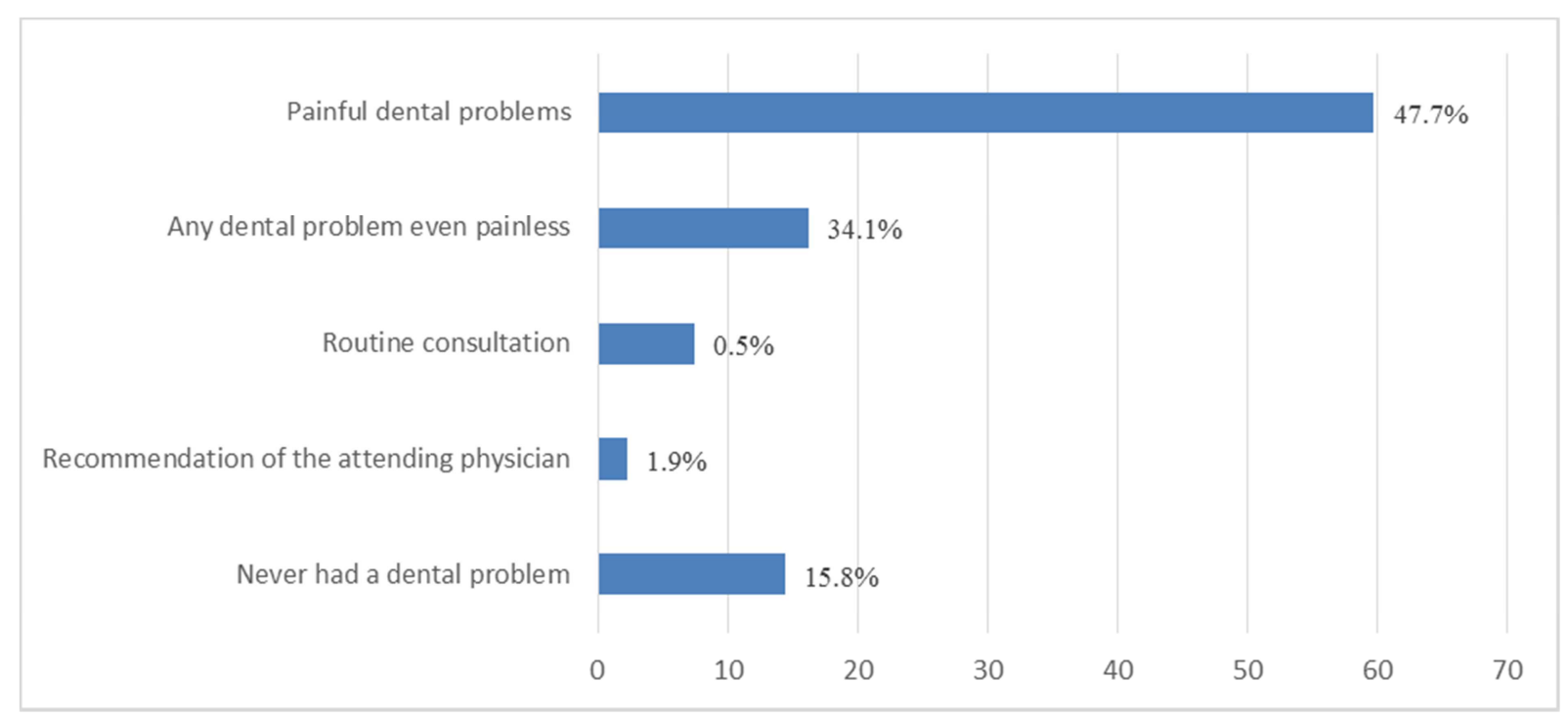

Figure 1. Distribution of respondents by attitudes towards an oral problem.

$47.7 \%$ of the beneficiaries used self-medication to cope with a dental problem, compared to $34.1 \%$ who consulted the dentist.

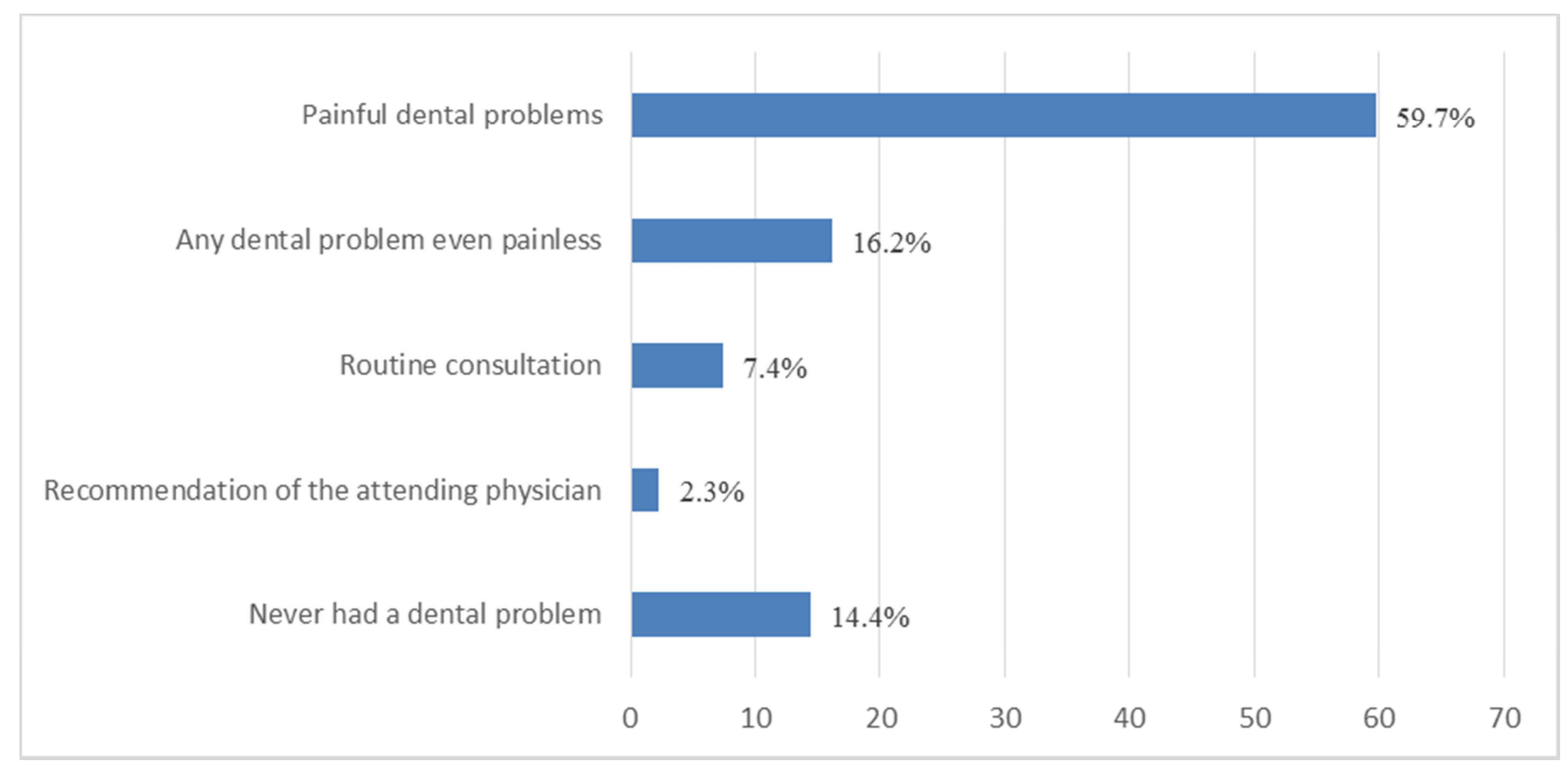

Figure 2. Distribution of beneficiaries according to the circumstance of the first use of the dentist. 
The majority of respondents $(59.7 \%)$ used a dentist because of pain.

\subsubsection{Renunciation to Oral Health Care}

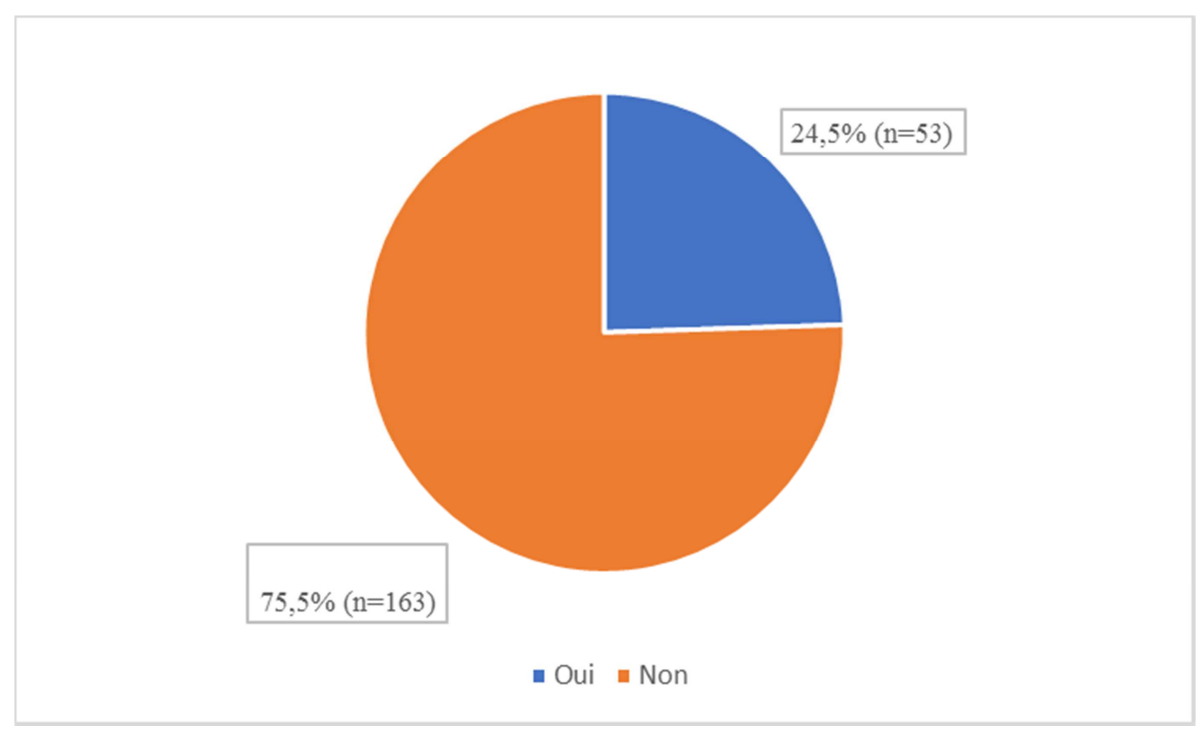

Figure 3. Distribution of beneficiaries of MUGEFCI according to the renunciation or not to oral care.

$24.5 \%$ (53 people) of the beneficiaries surveyed reported having given up oral health care at least once.

Table 5. Reasons for giving up oral health care $(n=53)$.

\begin{tabular}{lll}
\hline Reasons for the renunciation & Yes (n) & \% \\
\hline Lack of money & 25 & 47.2 \\
Lack of time & 6 & 11.3 \\
Care not reimbursed by the mutual insurance company & 6 & 11.3 \\
Negligence of dental care & 6 & 11.3 \\
Fear of the dentist & 2 & 15.1 \\
Presumed incompetence of the dentist & 2.8 \\
\hline
\end{tabular}

The main reasons for the cessation of oral health care for mutuals are the lack of money at $47.2 \%$ and the fear of dental care at $15.1 \%$.

\subsubsection{Perception of Mugefci Beneficiaries on Their Oral Status}

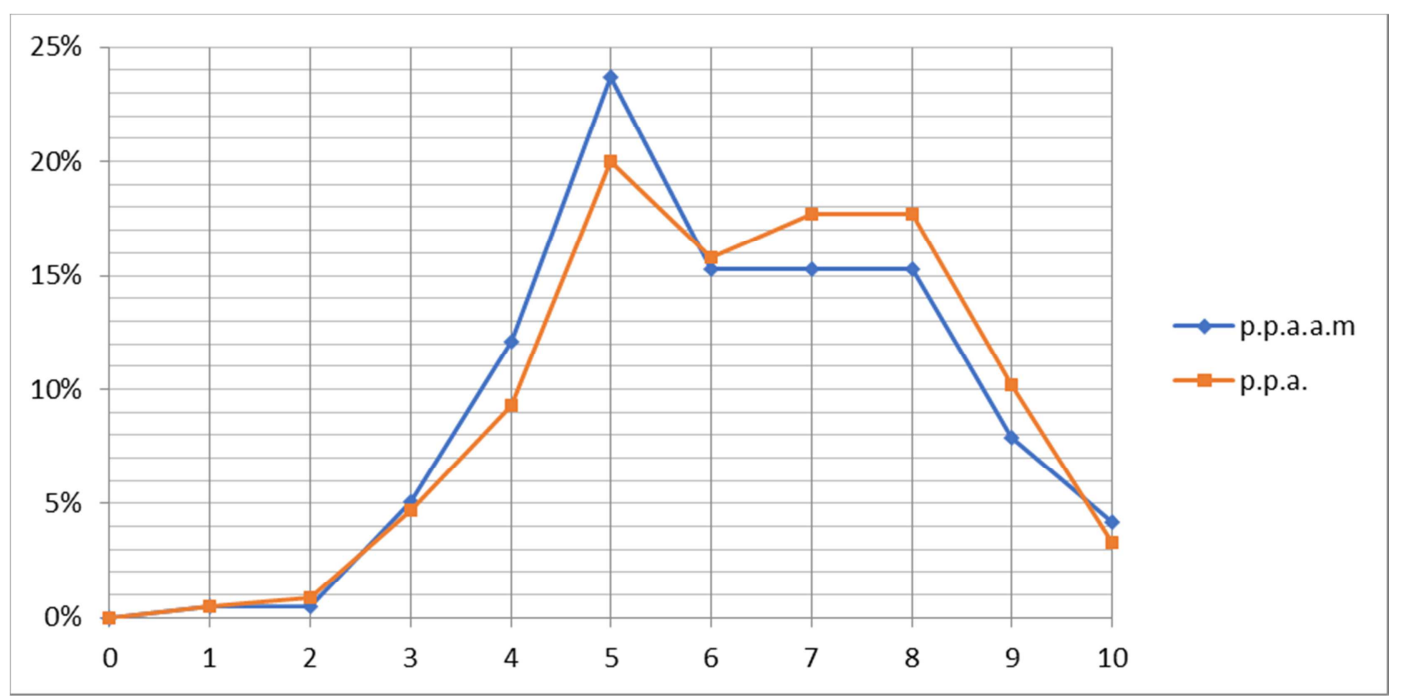

Figure 4. Members' perceptions of their oral health before and after joining the mutual.

p. p. a. a. $\mathrm{m}=$ personal perception before joining the mutual.

p. p. $a=$ current personal perception (at the time of the study). 
The two curves have the same look: the beneficiaries' perception of their state of health before joining the mutual and the one after seem to be identical.

\subsection{Financing of Oral Health Care}

Table 6. Perception of Mugefci beneficiaries on the amount of the contribution.

\begin{tabular}{lll}
\hline Modalities & Number (n) & Percentage (\%) \\
\hline Low & 15 & 6.9 \\
Affordable & 115 & 53.2 \\
High & 86 & 39.8 \\
Total & 216 & 100.0 \\
\hline
\end{tabular}

More than half of respondents $(53.2 \%)$ believe that the level of contributions is affordable. However more than a third $(39.8 \%)$ of the mutualists find it high.

Table 7. Willingness of Mugefci beneficiaries to pay more for oral care.

\begin{tabular}{lll}
\hline Willingness to pay more for oral care & Number (n) & Percentage (\%) \\
\hline Yes & 258 & 27.4 \\
No & 92 & 72.6 \\
Total & 216 & 100.0 \\
\hline
\end{tabular}

More than a quarter of the mutual's beneficiaries were willing to pay more to receive more oral health benefits.

\section{Discussion}

The study on access to dental care for members of Mugefci, Côte d'Ivoire's main mutual health organization, aimed to find out whether the removal of the financial obstacle was sufficient to have effective consumption of care. At first, we estimated the oral health care needs of mutualists. Our results showed that despite the existence of a costsharing mechanism, the dental care needs of Mugefci beneficiaries remained high. These needs were objectified by the high proportions of decayed (26.6\%) and absent (48.8\%) teeth in the study (Table 2). The DMF index was 4.7 for women compared to 3.9 for men corresponding to high and moderate levels of carious impairment respectively (Table 3). These results suggest a greater susceptibility of women to tooth decay. In Dakar (Senegal), in a student population, the average DMF for girls was 4 compared to 3.35 for boys [8], with a predominance of the decayed teeth index. The finding on the greater susceptibility of women to dental caries compared to men was made in Asia by Lukacs [9]. For this author, the decrease in the decay protection factor in women would be related to the succession of repeated physiological events (puberty, menstruation and pregnancy). However, our results differ from those of Esclassan et al $[10,11]$. Indeed, in a paleo-pathological study in an adult medieval population in France, these authors observed a higher carious prevalence among men (15.1\%) compared to women (13.7\%) although this difference was not statically significant. In addition, the proportion of filled teeth is higher among women than men (Table 3), suggesting that women have used oral health care services more than men. This reality is objectified by the ratio between the number of filled teeth and the total number of decayed, missing and filled teeth $(\mathrm{F} / \mathrm{DMF}=27.92 \%$ against $21.17 \%$ for men). The female propensity for oral health care was also highlighted in two other studies: one conducted in France in 2005 by Azogui- Levy and Rochereau [12] and the other in the United States by Shaffer et al. in 2015 [13]. However, in our study we did not observe a statistically significant difference $(p=0.558)$ between men and women in their perception of oral health care needs. This result suggests that the use of the health system for the management of oral diseases is not related to the importance that populations attach to oral health as an essential and necessary component of maintaining overall good health.

Self-medication is the first therapeutic option among the mutualists $(47.7 \%)$ (Figure 1) and pain was the primary reason for consultation with the dentist (Figure 2). This recourse to self-medication favors late consultations and is more pronounced for low-income people, as attested by a study conducted in India in 2015 [14]. These late consultations in odonto-stomatology, are related to the poverty and ignorance of the populations, who very often take anti-inflammatory to calm the pain. This can cause other complications $[15,16]$. Regarding the use of oral care, our results show that despite the existence of a means of payment to cover the cost of care, $24.5 \%$ of respondents said they gave up oral health care (Figure 3). The main reason for giving up care was the lack of financial means (for $47.2 \%$ of beneficiaries who gave up) (Table 5). In Brazil too, it has been shown that low-income people have limited access to oral health care [17]. Lack of financial resources remains a major obstacle to access to oral health care in developing countries $[18,19]$. However, to mention financial difficulties as an essential reason for the waiver of oral health care for people covered by insurance seems surprising, in that this prepayment mechanism is supposed to remove the financial barrier related to access to health care. In this regard, a study carried out in Senegal on the financial accessibility of health care showed that these difficulties were related to the lack of information of insured persons on the covered care and the inadequacy of the covered care that did not meet the needs of the insured [20]. Indeed, oral health care accounts for a significant portion of the health portfolio of insurance companies because of its perceived high cost [21]. For financial profitability, some care (prosthetic and orthodontic care) is poorly or not reimbursed by them. This situation encourages some people to forego oral health care. Finally, insurance does not meet their health needs [21].

Thus, in our study, we did not observe any significant change in the beneficiaries' perception of their state of health before and after their enrolment. This average score of their perception of their state of health before joining the mutual was $6.16 \pm 1.91$ compared to $6.35 \pm 1.90$ after joining (at the time of the study) (Figure 4). The majority of respondents therefore did not perceive the positive effects of Mugefci coverage on their oral health.

In view of this situation, we were interested in the 
willingness to pay for oral health care for Mugefci beneficiaries. It is defined as the maximum amount in monetary terms that an individual would be willing to sacrifice to obtain the benefits of a program, a benefit [22]. More than a third of those surveyed (53.2\%) rated the amount assessed as appropriate (table 5) and less than $1 / 3$ of the beneficiaries interviewed were willing to contribute more for better oral health care (table 6). This small number of people willing to increase their level of contribution to receive adequate care could be linked to the fact that they are people who already contribute to the financing of their health because they have insurance. In the study of 300 heads of households in Senegal [20], the number of people willing to contribute more was relatively higher $(41.9 \%)$. However, in the same country in the Department of Thies, $70 \%$ of members of a mutual health insurance company were in favour of increasing their contribution to better care for their oral health [23]. Tan et al; in a literature review showed that in reality, a person's willingness to pay for oral health care was related to their ability to pay and their interest in the benefits covered [24].

\section{Conclusion}

This study showed the oral health care needs of Mugefci beneficiaries remain important despite the existence of a prepayment mechanism. Removing the financial barrier of access to care does not always guarantee good oral health. Indeed, if access to health care is necessary for access to health care, it is not sufficient to guarantee it because the behavior of the patients as well as the care producers and the incentives to achieve quality care are fundamental. The challenges to be met in order to guarantee people's good accessibility to oral health care depend on the effective availability of this care, their affordability and finally their acceptability by the people who need it. Thus, the availability of a quality care offer, the extent of insurance coverage and information to beneficiaries about the services offered are factors to be taken into account to ensure effective consumption of oral health care and thus to improve oral health.

\section{Authors' Statement}

The informed consent of the respondents was obtained prior to their participation in the study. Each study participant was briefed on the study objective and confidentiality was assured for any information provided.

\section{References}

[1] Sen A. Why and how is health a human right? Lancet. 2008; 372 (9655): 2010.

[2] Habib SS, Perveen S, Khuwaja HM. The role of micro health insurance in providing financial risk protection in developing countries--a systematic review. BMC Public Health. 2016; 16: 281.

[3] World health organization. Health system financing: the path to universal coverage. World health report 2010.

[4] Audibert M, Mathonnat J, Roodenbeke E. Health financing in low-income countries in Africa and Asia. Problem and overview. Ed. Karthala, 2003; 5-37.

[5] Letourmy A. The development of health insurance in lowincome countries: the example of African countries. Rev. Biologies 2008. 331 (51): 952-963.

[6] Samba M., Kouadio NGA., Guinan JC, Da-Danho TV, Bakayoko-Ly R. Renunciation of oral care. Rev. Col. Odonto-Stomatol. Afr. Chir. Maxillo-fac. 2003; 10 (3): 5257.

[7] Sangare AD, Samba M, Guinan JC, et al. Socio demographic factors associated with renunciation to oral care in Côte d' Ivoire. MOJ Public Health. 2017; 6 (1): 241-248.

[8] Faye D, Cisse D, Mbodj EB, Lo CMM. Etude Epidemiological study of tooth decay among students at the Centre of University Works of Dakar. Odonto-stomatol trop 2007; 30 (3): 29-36.

[9] Lukacs JR. Gender differences in oral health in South Asia: meta data imply multifactorial biological and cultural causes. Am J Hum Biol. 2011; 23 (3): 398-411.

[10] Ecclasan R, Grimoud AM, Ruas MP, Sevin A, Pomar P, Crubézy E. Caries, usure et alimentation au sein de la population médiévale de Vilarnau d'Amont. Actes. Société française d'histoire de l'art dentaire, 2010; 15: 16-21.

[11] Esclassan R, Astie F, Sevin A, Donat R, Lucas S, Grimoud AM. Study of the prevalence and distribution of dental caries in a medieval population in Southwest France. Rev Stomatol Chir Maxillo fac. 2008; 109 (1): 28-35.

[12] Azogui - Levy S, Rochereau T. Behaviours in the use of oral and dental care and health: use of the "health and social protection" survey 2000. Question d'économie de la santé $2005 ; n^{\circ} 94$.

[13] Shaffer Jr, Leslie Ej, Feingold E. Caries experience differs between females and males across age groups in northern Appalachia. Int. J. Dent. 2015: 938213.8 p.

[14] Jaiswel AK, Pachava S, Sanikommu S, Rawlani SS, Pydi S, Ghanta B. Dental pain and self-care: a cross-sectional study of people with low socio-economic status residing in rural India. Int Dent J. 2015; 65 (5): 256-260.

[15] Ajayi DM, Arigbede AO. Barriers to oral health care utilization in Ibadan, South West Nigeria. Afr Health Sci. 2012; 12 (4): 507-513.

[16] Drabo R, Sangare A D, Samba M, Guinan J C. Accessibility to Oral Health Care in Peri-Urban Areas of Burkina Faso: Qualitative Survey on the Perceptions of the Populations of Kaya Health District. World J Public Health 2019; 4 (1): 2023.

[17] Carreiro DL, Souza JGS, Coutinho WLM, Haikal DS, Martins AMEBL. Access to dental services and related factors: a home-based population study. Cien Saude Colet. 2019; 24 (3): 1021-1032.

[18] Lo CM, Cisse D, Faye D, Faye B, Diouf M, Sarr M, Diallo PD. Factors associated with renunciation of oral care in Senegal. Lettre de Santé Publique bucco-dentaire 2010; 1: 811 . 
[19] Sangare AD, Samba M, Guinan JC, Diouf M, Bakayoko-Ly R, Bourgeois D. Socio Demographic Factors Associated with Renunciation to Oral Care in Côte d'Ivoire. MOJ Public Health 2017; 6 (1): 00156.

[20] Diop M, Kanoute A, Diouf M, Ndiaye A D, Lo CMM, Faye D, Cisse D. Financial Access to Dental Care Through Health Insurance in Senegal. Science J Public Health. 2017; 5 (5): 359-364.

[21] Diop M, Kanoute A, Diouf M, Ndiaye AD, Lo CMM, Faye D, Cisse D. The role of health insurance in the coverage of oral health care in Senegal. J Public Health Afr. 2018; 9 (3): 772.
[22] Olsen J, Smith R. Theory versus practice: a review of « willingness to pay $\gg$ in health and health care. Health Econ 2001; 10: 39.52 .

[23] Lo CMM, Faye D, Cisse D, Diouf M, Faye B, Fall A. Oral health care coverage by mutual insurance companies in the Thiès department. Rev. Col. Odonto-stomatol. Afr. Chir. Maxillo-fac. 2008; 15 (4): 28-32.

[24] Tan SHX, Vernazza CR, Nair R. Critical review of willingness to pay for clinical oral health interventions. J Dent. 2017; 64: 1-12. 